\title{
ANALISIS PENGELOLAAN JOURNAL OF COASTAL DEVELOPMENT UNIVERSITAS DIPONEGORO
}

\author{
Dhian Agustin Widyaningrum, Endang Fatmawati \\ Program Studi Ilmu Perpustakaan, Fakultas Ilmu Budaya \\ Universitas Diponegoro
}

\begin{abstract}
Abstrak
Penelitian ini bertujuan mengetahui pengelolaan Journal of Coastal Development Universitas Diponegoro. Metode penelitian yang digunakan adalah kualitatif deskriptif dengan pendekatan studi kasus. Informan dalam penelitian ialah 2 (dua) orang pengelola Journal of Coastal Development. Pengumpulan data dilakukan dengan observasi, wawancara mendalam, dan dokumentasi. Teknik analisis dalam penelitian ini adalah reduksi data, penyajian data, dan penarikan kesimpulan. Hasil penelitian menunjukkan bahwa pengelolaan Journal of Coastal Development sudah cukup baik tetapi masih perlu diperbaiki dalam hal cakupan informasi, bentuk informasi, dan alur perlakuan naskah.
\end{abstract}

Kata kunci: pengelolaan, jurnal ilmiah, Journal of Coastal Development, Universitas Diponegoro

\begin{abstract}
This research aims to determine the management of Diponegoro University's Journal of Coastal Development. The method used is qualitative descriptive with a case study approach. Informants in this study were two managers of the Journal of Coastal Development. Data were collected through observation, in-depth interviews, and documentation. Data analysis techniques are data reduction, data display, and conclusion. The results show that the management of the Journal of Coastal Development is good enough but still needs to be improved in terms of information coverage, information form, and the management of processing scripts. The managers are recommended to make some improvements in terms of information coverage, information form, and the management of processing scripts.
\end{abstract}

Keywords: management, scientific journals, Journal of Coastal Development, Diponegoro University 


\section{PENDAhUluan}

Perkembangan teknologi informasi yang berkembang pesat seperti sekarang ini juga memberikan pengaruh dalam publikasi dari suatu hasil penelitian. Publikasi hasil penelitian tidak lagi hanya terfokus pada media cetak tetapi juga media elektronik, seperti hanya internet. Media cetak saat ini perlahan sudah mulai ditinggalkan karena memerlukan biaya yang cukup besar dalam pencetakannya.

Teknologi tidak hanya mempengaruhi publikasi itu sendiri, tetapi juga berpengaruh pada tuntutan pembaca. Pembaca publikasi ilmiah saat ini menuntut untuk memperoleh informasi yang ia butuhkan secara cepat, murah, dan tanpa adanya batasan tempat serta waktu. Selain itu, adanya kebebasan tidak hanya dalam hal membaca tetapi juga mengunduh dan mengunggah publikasi ilmiah.

Salah satu bentuk publikasi ilmiah adalah jurnal ilmiah. Jurnal ilmiah biasanya diterbitkan oleh perguruan tinggi, baik negeri maupun swasta. Adanya berbagai tuntutan dari para pembaca publikasi ilmiah memberikan dampak dalam penerbitannya. Agar dapat memenuhi segala tuntutan tersebut maka jurnal ilmiah tentunya harus dikelola dengan baik. Pengelolaan jurnal ilmiah tentunya akan berpengaruh pada kualitas jurnal itu sendiri, baik dalam hal kandungan isinya maupun secara tampilan jurnal ilmiah.

Pengelolaan jurnal ilmiah berbeda dengan pengelolaan terbitan lain. Hal ini disebabkan sifat keilmiahan yang dimiliki oleh jurnal. Sifat khas ini membuat lembaga penerbit, cakupan informasi, tujuan penerbitan, pengelolaan naskah dari jurnal ilmiah lebih kompleks. Oleh karena itu, diperlukan pengelolaan yang baik agar dapat menghasilkan jurnal ilmiah yang baik dan berkualitas. 


\section{LANDASAN TEORI}

\subsection{Publikasi Ilmiah}

Publikasi ilmiah itu merupakan salah satu bagian dari terbitan berkala. Terbitan berkala dalam konteks ini berarti publikasinya direncanakan terbit secara berkelanjutan. Sajiannya berisi informasi baru yang menarik dan ditulis oleh beberapa orang. Terbitan berkala pada umumnya berisi mengenai hal-hal yang bersifat khusus sehingga informasi yang ada dalam publikasi berkala terus-menerus dikembangkan (Middleton, 2002: 101).

Publikasi ilmiah menurut Robandi (2008) merupakan salah satu indeks performansi dari para peneliti, akademisi ilmuwan maupun guru. Kualitas dari para peneliti dapat dilihat dari kualitas tulisannya. Selain itu, jumlah publikasi ilmiah dan jumlah institusi lain yang mengacu pada hasil penelitian sebuah perguruan tinggi tersebut juga dijadikan unsur dalam akreditasi perguruan tinggi.

\subsection{Pengertian Jurnal Ilmiah}

Jurnal ilmiah termasuk dalam terbitan berkala. Jurnal ilmiah adalah salah satu jenis majalah yang berisi artikel hasil penelitian maupun informasi ilmiah dari suatu bidang keilmuan. Jurnal ilmiah lebih pada umumnya memuat naskah berupa hasil penelitian, laporan, maupun tulisan ilmiah lainnya. Lasa (2009: 128) menyebutkan bahwa jurnal adalah publikasi ilmiah yang memuat informasi tentang hasil kegiatan dalam bidang ilmu pengetahuan dan teknologi minimal harus mencakup kumpulan atau akumulasi pengetahuan baru, pengamatan empiris, dan pengembangan gagasan atau usulan.

Lebih lanjut Lasa (2009: 129) juga memberikan pengertian tersendiri mengenai jurnal penelitian, yaitu publikasi ilmiah yang menyajikan artikel hasil penelitian primer dan dimaksudkan 
sebagai media komunikasi antar penulis, antar ahli, dan antar ilmuwan tingkat nasional maupun tingkat internasional.

\subsection{Jenis-jenis Jurnal Ilmiah}

Jurnal-jurnal yang terbit di kalangan perguruan tinggi mempunyai jenis yang berbeda. Perbedaan ini disebabkan oleh jenis penelitian di perguruan tinggi lebih kompleks dan beragam. Saukah dalam Rachmawati (2008: 173) mengelompokkan sebagai berikut:

\section{a. Jurnal Ilmiah Lokal}

Jurnal ilmiah lokal berisi karya ilmiah maupun artikel hasil penelitian yang ditulis oleh dosen-dosen dari perguruan tinggi itu sendiri. Pengelolaan dari jurnal ini berasal dari kalangan sendiri dan artikel yang termuat di dalam jurnal disunting oleh para dosen dari dalam perguruan tinggi. Jurnal ilmiah lokal didiseminasikan secara terbatas, hanya untuk kalangan perguruan tinggi tersebut.

\section{b. Jurnal Ilmiah Nasional Tidak Terakreditasi}

Jenis jurnal ini memiliki kontributor atau penulis yang sebagian besar berasal dari luar lingkungan perguruan tinggi. Proses penyuntingan naskah melibatkan pakar dari luar lingkupnya. Penyebaran jurnal telah secara nasional bukan lagi hanya untuk kalangan sendiri. Namun dalam sisi tampilan dan isinya, jurnal belum memenuhi kriteria akreditasi yang ditetapkan oleh Direktorat Jenderal Pendidikan Tinggi (DIKTI) maupun LIPI.

c. Jurnal Ilmiah Nasional Terakreditasi

Jurnal ilmiah nasional terakreditasi pada dasarnya sama dengan jurnal ilmiah nasional tidak terakreditasi. Perbedaan yang 
terdapat pada jurnal ini adalah tampilan dan isinya. Tampilan dan isi jurnal telah memenuhi kriteria akreditasi.

d. Jurnal Ilmiah Internasional

Jurnal ilmiah internasional adalah jurnal yang telah memiliki reputasi di kalangan peneliti tingkat internasional. Artikel yang dimuat merupakan tulisan ataupun hasil-hasil penelitian dari kalangan peneliti bukan hanya dalam negeri tetapi juga luar negeri. Adanya keterlibatan pakar internasional sebagai penyunting naskah membuat jurnal memiliki kualitas yang baik. Jenis jurnal ini sudah dilakukan diseminasi secara global.

\subsection{Pengelolaan Jurnal Ilmiah}

Pengelolaan jurnal ilmiah di Indonesia telah mempunyai aturan yang ditetapkan oleh Direktorat Jenderal Pendidikan Tinggi (DIKTI), Kementerian Pendidikan dan Kebudayaan khususnya Direktorat Penelitian dan Pengabdian pada Masyarakat. Biasanya setiap penerbit jurnal memiliki kebijakan tersendiri yang tetap mengacu pada peraturan tersebut. Hal ini terjadi karena setiap jurnal mempunyai kekhasan masing-masing.

Lembaga penerbit jurnal ilmiah hasil penelitian banyak dari kalangan perguruan tinggi. Hal ini tidak lepas dari peran perguruan tinggi yang tercantum dalam Tri Dharma Perguruan Tinggi. Penerbitan sebuah jurnal di perguruan tinggi dikelola oleh lembaga penelitian masing-masing perguruan tinggi baik negeri maupun swasta.

Sebuah lembaga penerbit jurnal sebaiknya dapat mengelola jurnal secara mapan, memiliki kekuatan dan ketetapan hukum, serta memiliki dukungan dana untuk menjamin keberlangsungan penerbitan jurnal (LIPI, 2011: 22). Pedoman akreditasi majalah ilmiah yang diterbitkan oleh LIPI (2011) menyebutkan bahwa 
lembaga penelitian dapat bekerja sama dengan organisasi profesi ilmiah. Kerja sama ini dapat memberikan keuntungan yang besar bagi lembaga penelitian karena lembaga tersebut mendapatkan dukungan keilmuan paling besar. Hal ini baik dari kesesuaian bidang ilmu, sumber daya pengelola, maupun objek penelitian.

Pengelolaan artikel jurnal ilmiah hasil penelitian mempunyai proses yang memakan waktu paling lama dalam proses penerbitan dan melibatkan banyak pihak. Artikel hasil penelitian yang dikirimkan oleh para kontributor atau penulis tidak bisa langsung diterbitkan. Artikel yang telah masuk kepada Dewan Redaksi kembali dikoreksi baik oleh kalangan dewan redaksi, reviewer atau mitra bestari.

Menurut Pusbindiklat Lembaga Ilmu Pengetahuan Indonesia, manajemen naskah dalam jurnal ilmiah melalui beberapa tahapan. Pertama, yang harus dilalui setelah naskah diterima ialah sidang penyunting. Sidang penyunting diadakan untuk menentukan penyuntingan naskah mulai dari format penulisan hingga kebahasaan. Selain itu, sidang penyunting juga menentukan mitra bestari yang akan menyunting dari segi isi naskah.

Kedua, tahapan sidang penyunting selesai ketua dewan redaksi akan menentukan naskah diterima, diperbaiki atau ditolak. Keputusan diambil dengan mempertimbangkan hasil penyuntingan dan saran yang diberikan oleh mitra bestari. Naskah akan kembali ke penulis untuk dilakukan koreksi ulang maupun perbaikan. Ketiga, pencetakan artikel sehingga siap untuk diterbitkan.

Struktur redaksi jurnal ilmiah hasil penelitian yang baik ialah yang melibatkan unsur-unsur dewan redaksi, ketua dewan redaksi, redaksi pelaksana. Dewan redaksi ialah dewan yang terdiri dari para pakar dengan keahlian sesuai bidang keilmuan 
majalah ilmiah. Jurnal ilmiah hasil penelitian memiliki dewan redaksi yang berperan sebagai narasumber dan pengambil keputusan terakhir apabila terjadi perbedaan pendapat mengenai penerbitan artikel (LIPI, 2011: 23). Dewan redaksi mempunyai fungsi sebagai jembatan antara penulis artikel ilmiah dan pembacanya (Wibowo, 2008: 18).

Selanjutnya mitra bestari merupakan orang yang ahli atau pakar yang ditunjuk oleh dewan redaksi untuk meninjau atau menelaah naskah sebelum naskah diterima atau ditolak penerbitannya. Mitra bestari adalah pakar yang ditunjuk oleh dewan redaksi sebagai penilai yang telah diakui kepakarannya oleh rekan-rekan sejawatnya dan dibuktikan dengan hasil publikasi ilmiahnya (LIPI, 2011). Sementara itu, Wasmen Manalu (2011) menyebutkan mitra bestari merupakan wasit yang merupakan kelompok peninjau atau penelaah naskah sebelum diputuskan untuk diterima atau ditolak penerbitannya.

Substansi atau isi pokok dari jurnal meliputi bentuk artikel atau naskah, cakupan keilmuan dan kualitas informasi dari naskah.

Jurnal ilmiah dapat berisi beberapa bentuk artikel, tetapi akan lebih baik apabila jurnal tersebut menyajikan artikel-artikel hasil penelitian.

Hasil penelitian dapat berupa hasil penelitian primer maupun sekunder. Hasil penelitian primer merupakan hasil penelitian yang berdasarkan penelitian asli (pertama). Sementara itu, hasil penelitian sekunder adalah hasil penelitian yang berdasarkan penelitian yang sudah dilakukan sebelumnya atau menggunakan data yang telah tersedia.

Kualitas informasi (quality of information) dalam Sutabri (2005: 35) dapat dilihat dari tiga hal, yaitu akurat (accurate), tepat waktu (timelines), dan relevan (relevance). Proses penyebarluasan suatu 
informasi dapat dilakukan dengan berbagai cara dan menggunakan media yang beragam begitu pula dalam proses menyebarluaskan informasi seperti jurnal. Jurnal ilmiah hasil penelitian merupakan alat atau sarana yang digunakan oleh peneliti untuk mempublikasikan hasil penelitiannya kepada masyarakat.

Sebelum menyebarluaskan atau mempublikasikan jurnal ilmiah, pengelola hendaknya mengetahui siapa yang menjadi sasaran pembaca (target reader) dari jurnal yang mereka kelola. Sasaran pembaca akan menentukan bagaimana arus penyebaran suatu informasi.

\section{METODE PENELITIAN}

Metode yang digunakan adalah metode kualitatif dengan jenis penelitian deskriptif dan pendekatan studi kasus. Penelitian deskriptif merupakan penelitian yang melakukan analisis hanya pada taraf penggambaran yaitu menganalisis dan menyajikan fakta secara sistematik sehingga lebih mudah dipahami (Azwar, 2009: 6). Pendekatan studi kasus dapat membantu peneliti untuk memperoleh data yang diperlukan. Studi kasus menghasilkan kesimpulan dari suatu kekhususan dan hasil dari penelitian ini bersifat khusus (Sulistyo-Basuki, 2006: 113). Subjek yang diteliti merupakan dua orang pengelola Journal of Coastal Development. Sementara itu, objek yang menjadi fokus penelitian adalah pengelolaan Journal of Coastal Development.

Penelitian menggunakan jenis data kualitatif, dengan sumber data primer dan sekunder. Data primer adalah data yang diperoleh peneliti langsung dari para informan. Selanjutnya data sekunder adalah data yang diperoleh dari sumber tidak langsung. Sumber data ini didapatkan dari buku, jurnal ilmiah, dan penelitian terdahulu. 
Teknik pengumpulan data dengan observasi, wawancara mendalam, dan dokumentasi. Observasi merupakan kegiatan pengamatan yang dilakukan langsung terhadap objek penelitian untuk memperoleh data yang lebih lengkap. Wawancara mendalam dengan melakukan wawancara atau bertanya langsung kepada informan secara mendalam mengenai permasalahanpermasalahan pengelolaan Journal of Coastal Development. Dokumentasi dilakukan dengan menggali data dan informasi dari dokumen dan literatur yang berkaitan dengan permasalahan.

Teknik analisis data dilakukan dengan reduksi data, penyajian data, dan penarikan kesimpulan. Reduksi data merupakan proses menggolongkan, merangkum, dan membuang data yang tidak diperlukan, agar data yang sudah diperoleh mudah untuk dianalisis. Reduksi data mempermudah dalam penarikan kesimpulan akhir.

Penyajian data pada penelitian kualitatif dapat berupa teks naratif, bagan, grafik, maupun matriks. Penelitian menggunakan teks naratif dalam penyajian data yang telah diperoleh. Penarikan kesimpulan dilakukan setelah semua data direduksi dan disajikan. Kesimpulan dalam penelitian kualitatif mungkin dapat menjawab permasalahan, tetapi mungkin juga tidak. Kesimpulan penelitian kualitatif merupakan temuan baru yang belum pernah ada. Temuan dapat berupa deskripsi, hubungan kausal, hipotesis maupun teori.

\section{HASIL DAN PEMBAHASAN}

\section{a. Kelembagaan Penerbit}

Lembaga penerbit dari Journal of Coastal Development adalah Lembaga Penelitian dan Pengabdian kepada Masyarakat (LPPM) Universitas Diponegoro (Undip) yang bekerjasama dengan 
organisasi profesi ilmiah, Ikatan Sarjana Oseanologi Indonesia (ISOI) dan lembaga penerbit jurnal ilmiah elektronik OMICs Group.

Cakupan informasi dari Journal of Coastal Development merupakan informasi mengenai topik-topik bidang pesisir pantai dan laut. Bidang keilmuannya tidak hanya dari bidang sains namun juga bidang sosial humaniora.

Journal of Coastal Development diterbitkan dengan tujuan sebagai identitas keilmuan Undip, media komunikasi universitas, indikator kegiatan penelitian di lingkungan universitas, dan sebagai wadah untuk mendiseminasikan hasil-hasil penelitian bidang pesisir pantai dan laut yang menggunakan bahasa Inggris di Indonesia. Bentuk informasi yang dimuat di Journal of Coastal Development yaitu berupa artikel hasil penelitian dan kajian ilmiah atau review artikel.

\section{b. Pengelolaan Naskah}

Pengelola Journal of Coastal Development memperoleh naskah dari berbagai pihak. Cara memperoleh naskah dengan cara menyebarkan leaflet, flyer, serta membuka stand pada saat pertemuan-pertemuan guna untuk memperoleh naskah yang sesuai dengan kriteria yang telah ditetapkan. Selain dari hal-hal tersebut, kerja sama dengan ISOI juga memudahkan pengelola mendapatkan naskah. Namun saat ini sudah ada sistem yang memudahkan yaitu melalui submit dengan menggunakan Open journal System (OJS).

Dari hasil wawancara yang dilakukan peneliti menunjukkan bahwa pengiriman naskah yang akan dimuat di Journal of Coastal Development melalui tiga cara. Tiga cara tersebut ialah pengiriman dalam bentuk hard copy, pengiriman melalui surat elektronik atau e-mail, melalui pengiriman secara online melalui website, serta 
melalui OJS. Dari keempat cara tersebut, pengiriman melalui OJS menjadi pilihan dan lebih sering digunakan oleh para penulis.

Alur perlakuan naskah dimulai dari tahapan penelaahan format dan bahasa oleh pengelola. Tahapan ini dilakukan untuk meneliti bahasa dan tata letak yang digunakan oleh penulis. Hal ini dilakukan karena Journal of Coastal Development merupakan jurnal ilmiah berbahasa Inggris. Tahap selanjutnya yaitu pengiriman naskah kepada reviewer atau orang yang ahli pada bidang tertentu. Penunjukkan reviewer disesuaikan dengan isi naskah dengan keahlian atau kepakaran yang dimiliki oleh reviewer tersebut. Tahapan kedua ini menentukan apakah naskah diterima, ditolak, atau diterima dengan perbaikan. Selanjutnya tahapan proses gale proof. Proses gale proof dilakukan setelah perbaikan naskah oleh penulis selesai. Gale proof merupakan proses di mana naskah diteliti kembali apabila ada kesalahan penulisan dan dilakukan formatting sesuai dengan format cetak. Setelah semua tahapan atau proses selesai, tahapan selanjutnya adalah melakukan penerbitan secara online kemudian pencetakan naskah.

\section{c. Kualitas Informasi}

Dari pernyataan yang diberikan informan dapat diambil kesimpulan bahwa kualitas informasi dari naskah yang dimuat dalam Journal of Coastal Development diukur dengan standar yang telah ditetapkan oleh pengelola. Standar penilaian digunakan agar penilaian dilakukan secara objektif dan bersifat sama untuk setiap naskah.

\section{d. Review Naskah}

Hasil wawancara menunjukkan bahwa proses review naskah pada Journal of Coastal Development menggunakan sistem blind 
review. Sistem blind review merupakan penelaahan naskah tanpa mencantumkan nama dan instansi asal dari penulis. Sistem review yang demikian dipilih untuk menjaga keobjektifan dan keadilan pada saat reviewer melakukan penelaahan.

\section{e. Struktur Keredaksian}

Struktur redaksi dari Journal of Coastal Development terdiri dari: ketua dewan redaksi, penyunting pelaksana, asisten editor, dan anggota dewan editor. Anggota dari redaksi ini telah mempunyai tugas dan tanggung jawab masing-masing sehingga tidak ada tumpang tindih pekerjaan dalam mengelola Journal of Coastal Development.

\section{f. Mitra Bestari}

Mitra bestari dari Journal of Coastal Development berasal dari berbagai kalangan mulai dari dosen, peneliti, maupun para ahli yang berasal dari organisasi non-pemerintahan. Jumlah mitra bestari bersifat variatif, tergantung dari keilmuan yang dimiliki mitra bestari dengan cakupan keilmuan dari naskah.

\section{g. Penyebarluasan Informasi}

Penyebarluasan informasi yang dimaksud adalah penyebarluasan dari Journal of Coastal Development. Penyebarluasan Journal of Coastal Development menggunakan media cetak dan media elektronik yaitu internet. Sejak tahun 2010, Journal of Coastal Development sudah masuk ke lembaga pengindeks internasional antara lain: DOAJ, EBSCO, J-GATE, dan COPERNICUS.

\section{h. Faktor Pendukung}


Faktor yang mendukung dari penerbitan Journal of Coastal Development yaitu bahasa yang digunakan bahasa Inggris yang merupakan bahasa internasional. Jadi dalam hal ini dapat dibaca dan dimanfaatkan oleh pembaca di seluruh dunia. Kerjasama yang terjalin dengan ISOI membuat Journal of Coastal Development semakin baik dalam hal kualitas artikel dan kesempatan memperoleh artikel yang berkualitas semakin besar; sumber daya manusia yang dimiliki oleh Journal of Coastal Development cukup memberikan pengaruh positif karena telah memahami dan mengerti pengelolaan sebuah jurnal ilmiah yang baik.

\section{i. Kendala}

Kendala dalam pengelolaan Journal of Coastal Development yaitu pertama, biaya pencetakan yang cukup besar padahal pengelola harus menyediakan jurnal cetak yang tidak sedikit. Kedua, pengelola kesulitan melakukan regenerasi karena mengelola jurnal ilmiah bagi sebagian besar orang merupakan hal tidak mudah dilakukan karena membutuhkan komitmen dan profesionalitas yang tinggi. Ketiga, penulis dan reviewer terkadang tidak mematuhi peraturan yang telah ditetapkan oleh pengelola. 


\section{PENUTUP}

Berdasarkan hasil penelitian dan pembahasan mengenai pengelolaan Journal of Coastal Development Universitas Diponegoro, dapat disimpulkan bahwa pengelolaan dari sebuah jurnal ilmiah dipengaruhi oleh beberapa faktor, yaitu kelembagaan penerbit, cakupan informasi, tujuan penerbitan, bentuk informasi, pengelolaan naskah, review naskah, struktur keredaksian, mitra bestari, serta penyebarluasan informasi. Dari analisis berbagai faktor tersebut, dapat disimpulkan bahwa pengelolaan Journal of Coastal Development sudah cukup baik. Namun demikian, sebagai saran bahwa masih perlu adanya perbaikan dalam hal cakupan informasi, bentuk informasi, serta alur perlakuan naskah. Bagi pengelola hendaknya melakukan perbaikan dalam hal cakupan informasi, bentuk informasi, dan alur perlakuan naskah. Selanjutnya juga adanya regenerasi pengelola yang dilakukan secara terbuka untuk mendapatkan pengelola yang memiliki komitmen, integritas, loyalitas, dan profesionalitas yang tinggi. Bagi penulis diharapkan mematuhi peraturan yang telah ditetapkan oleh pengelola jurnal, baik dalam hal aturan penulisan maupun batas waktu pengumpulan naskah hasil revisi. 


\section{DAFTAR PUSTAKA}

Azwar, Saifuddin. 2009. Metode Penelitian. Yogyakarta: Pustaka Pelajar.

Irianti, Pergola. 1999. Majalah Ilmiah dan Muatan Informasinya. Buletin Perpustakaan. Tersedia di http://lib.ugm.ac.id/data/pubdata/pusta/pirianti1.pdf.

Lasa Hs. 2009. Kamus Kepustakawanan Indonesia. Yogyakarta: Pustaka Book Publisher.

LIPI. 2011. Pedoman Akreditasi Majalah Ilmiah. Jakarta: Lembaga Ilmu Pengetahuan Indonesia. Tersedia di http:/ / www.litbang.depkes.go.id/sites/download/pedoman/p eraturan-peneliti/Pedoman-Akreditasi-Majalah-Ilmiah2011.pdf

Manalu, Wasmen. 2011. Kebijakan Pengembangan Jurnal Ilmiah Nasional. Tersedia http: / /journal.unpad.ac.id/mku/article/download/185/ 163

Middleton, Michael. 2002. Information Management: A Consolidation of Operations, Analysis, and Strategy. New South Wales: Center for Information Studies.

Rachmawati, Yuliana K. 2008. Aplikasi Web untuk Membantu Pengelolaan Jurnal. Jurnal Teknologi, 1(2), hal. 171-177.

Robandi, Imam. 2008. Becoming The Winner: Riset Menulis Ilmiah, Publikasi Hasil Penelitian, dan Presentasi. Yogyakarta: Andi Offset.

Sulistyo-Basuki. 2006. Metode Penelitian. Jakarta: Wedatama Widya Sastra.

Sutabri, Tata. 2005. Sistem Informasi Manajemen. Yogyakarta: Andi.

Wibowo, Wahyu. 2008. Piawai Menembus Jurnal Terakreditasi. Jakarta: Bumi Aksara. 